\title{
Serum antibody responses to Clostridium difficile toxin A: predictive and protective?
}

Kyne L, Warny M, Qamar A, et al. Association between antibody response to toxin $\mathrm{A}$ and protection against recurrent Clostridium difficile diarrhoea. Lancet 2001;357:189-93.

\section{Background}

We have reported that symptom-free carriers of Clostridium difficile have a systemic anamnestic immune response to toxin $\mathrm{A}$. The aim of this study was to determine whether an acquired immune response to toxin $\mathrm{A}$, during an episode of $C$. difficile diarrhoea, influences risk of recurrence.

\section{Methods}

We prospectively studied 63 patients with nosocomial C. difficile diarrhoea. Serial serum $\operatorname{IgA}, \operatorname{IgG}$, and $\operatorname{IgM}$ concentrations against $C$. difficile toxin $\mathrm{A}$, toxin $\mathrm{B}$, or non-toxin antigens were measured by ELISA. Individuals were followed for 60 days.

\section{Findings}

19 patients died (30\%). Of the 44 who survived, 22 had recurrent $C$. difficile diarrhoea. Patients with a single episode of $C$. difficile diarrhoea $(n=22)$ had higher concentrations of serum IgM against toxin A on day 3 of their first episode of diarrhoea than those with recurrent diarrhoea $(n=22, p=0.004)$. On day 12 , serum IgG values against toxin $\mathrm{A}$ were higher in patients who had a single episode of diarrhoea $(n=7)$ than in those who subsequently had recurrent diarrhoea $(n=9, p=0.009)$. The odds ratio for recurrence associated with a low concentration of serum IgG against toxin A, measured 12 days after onset of $C$. difficile diarrhoea, was 48.0 (95\% CI 3.5-663).

\section{Interpretation}

A serum antibody response to toxin $\mathrm{A}$, during an initial episode of $C$. difficile diarrhoea, is associated with protection against recurrence.

\section{Comment}

Clostridium difficile is a significant human pathogen causing a spectrum of diseases ranging from mild diarrhoea to fulminant pseudomembranous colitis and antibiotic associated diarrhoea, particularly in hospitalised patients. Morbidity and mortality rates are high, especially in the elderly. The main virulence factors of this non-invasive organism are toxin A (enterotoxin) and toxin B (cytotoxin).

This study examined serum antibody responses to toxin A, toxin B, and non-toxin antigen in 44 hospitalised patients diagnosed with $C$ difficile associated diarrhoea (CDAD). Serial serum samples were obtained for antibody measurement at entry to the study and every three days subsequent until discharge. Serum samples for each time point were not available for each individual. This, as Kyne et al report, weakens the study at the later time points. Serum levels of $\operatorname{IgA}, \operatorname{IgG}$, and IgM against toxin A, toxin B, and non-toxin antigens were measured by ELISA, although the report concentrates on the results for IgG and IgM against toxin A. Comparison was made between the median values for a group of patients with a single episode of CDAD $(n=22)$ and those experiencing recurrence $(\mathrm{n}=22)$. "C difficile diarrhoea" and "recurrence" are clearly defined in relation to this study.

By day 3, median serum values for $\operatorname{IgM}$ against toxin $\mathrm{A}$, toxin $\mathrm{B}$, and non-toxin antigens were higher in the group experiencing a single episode of CDAD $(p=0.004, p=0.02$, $\mathrm{p}=0.05$, respectively). This difference remained significant at day 6, 9, and 12 for $\operatorname{IgM}$ against toxin $\mathrm{A}$ with the median concentration of $\operatorname{IgM}$ increasing at each time point for the single episode group. However, median concentration fell slightly in the recurrent group. The median concentration of IgG against toxin A between groups was significantly higher in those with a single episode, but not until day 12 $(p=0.009)$. Levels of $\operatorname{IgM}$ against toxin $A$ at day 3 significantly correlated with levels of IgG at 12 days. The difference in IgG levels against toxin B and non-toxin antigen at day 12 were not significant. The only difference in serum IgA was against non-toxin antigen at day 6 where, interestingly, levels were higher in the group experiencing recurrence.

A number of variables included in this study were found to be significantly associated with recurrence, including age more than 65 years, increased severity of disease, CDAD on admission, and antibiotic use in the follow up period. The significantly higher levels of serum $\operatorname{IgM}$ against toxin A at day 3 combined with the higher serum IgG antitoxin A levels at day 12 suggest an acquired immune response by the single episode group. The delayed IgG response implies a primary immune response with respect to $C$ difficile infection.

An interesting comparison is a previous report where not only were levels of IgG against toxin A significantly higher in asymptomatic carriers of $C$ difficile compared with patients with CDAD, but high levels were attained within three days of colonisation compared with 12 days in this report. A systemic anamnestic response to toxin A in asymptomatic carriers is suggested. ${ }^{1}$ Kyne et al propose that the results of this study together with other reports ${ }^{12}$ provide strong evidence that the serum $\operatorname{IgG}$ immune response to $C$ difficile toxin A plays a substantial role in determining the clinical outcome of infection, asymptomatic carriage, and non-recurrent or recurrent CDAD. The authors' claim of predicting the risk of nosocomial and recurrent diarrhoea may be plausible in view of the levels of serum IgG at colonisation ${ }^{1}$ and at 12 days (this study).

The apparent lack of immune response in $50 \%$ of patients may well be the result of a poor response to the $C$ difficile species but differences in strains colonising patients may play some role. In this and a previous study, ${ }^{1}$ there were no data regarding the $C$ difficile isolates cultured from 
some of the patients in each group. Faecal culture was carried out on only some of the enrolled patients. Simultaneous carriage of toxigenic and non-toxigenic strains may influence the immune response. ${ }^{3}$ In addition, not all strains are equally virulent ${ }^{4}$; some pathogenic strains are toxin $\mathrm{A}$ negative/toxin B positive ${ }^{4}$ and some exhibit low levels of toxin gene transcription where toxin genes are present but expression and toxin secretion are minimal. ${ }^{5}$ These strain differences are likely to influence the immunogenicity of the colonising $C$ difficile organism.

Although predicting risk is important, it does not address the more important issue of prevention and control of CDAD. Because $C$ difficile is ubiquitous in the environment as a highly resistant spore, effective control by avoiding exposure to the organism is a laudable but foolhardy aspiration. Active or passive immunisation is perhaps a more reasonable long term aim.

Kyne et al state that a serum antibody response to toxin $\mathrm{A}$ is associated with protection against recurrence. This statement needs to be considered in light of what is known of the pathogenesis of CDAD. CDAD results from toxins produced within the intestinal lumen adhering to the mucosal epithelial surface and exerting cytotoxic effects. ${ }^{6}$ These elicit a local mucosal IgA response.

Could the reported serum responses be a reflection of a local intestinal mucosal response resulting in neutralising polymeric IgA blocking the binding of toxin A to intestinal epithelium and subsequent dramatic cytotoxic effect of toxin B? There is no correlation between antibody titre and toxin neutralising ability and in the serum of patients with diarrhoea, monomeric and polymeric IgA, but not IgG, have been implicated in $C$ difficile neutralisation. ${ }^{7}$ A study using polarised human colonic carcinoma cell monolayers reported that polymeric IgA (primarily intestinal) was more efficient in neutralising toxin A than monomeric IgA and IgG (primarily serum). It was suggested that a potent vaccine against $C$ difficile should elicit a strong mucosal polymeric IgA mediated immune response. ${ }^{8}$

Accurate determination of faecal IgA concentrations and the ratio of monomeric, dimeric/polymeric, and secretory IgA can be problematic. ${ }^{2}$ Despite this, faecal IgA, serum
IgA and IgG against toxin A and B, together with the toxin neutralising ability of each for single episode and recurrent patients, would go a long way towards determining which immunoglobilins are most protective, rather than most predictive or prevalent in CDAD. Early clinical trials of a vaccine are underway.

Between them, the authors have reported a number of studies examining various aspects of human immune responses to both symptomatic and asymptomatic $C$ difficile infections. This study revisits other studies ${ }^{2}{ }^{10}$ but is more powerful due to greater patient numbers, more frequent regular sampling, and finally by examination of the associations between other potentially predictive variables and recurrent diarrhoea.

C PHILLIPS

Department of Veterinary Pathology,

University of Edinburgh,

Easter Bush Veterinary Centre,

Roslin, Midlothian EH25 9RG, UK

cphillips@vet.ed.ac.uk

1 Kyne L, Warny M, Qamar A, et al. Asymptomatic carriage of Clostridium difficile and serum levels of IgG antibody against toxin A. $N$ Engl f Med 2000;342:390-7.

2 Warny M, Vaerman J-P, Avesani V, et al. Human antibody response to Clostridium difficile toxin A in relation to clinical course of infection. Infect

3 Borriello SP, Honour P. Concomitance of cytotoxigenic and noncytotoxigenic Clostridium difficile in stool specimens. F Clin Microbiol 1983; 18:1006-7.

4 Wilcox MH. Clostridium difficile infection: appendix. $\mathcal{F}$ Antimicrob Chemother 1998;41(suppl C):71-2.

5 Mathis JN, Pilkington L, McMillin DE. Detection and transcription of toxin DNA in nontoxigenic strain of Clostridium difficile. Curr Microbiol 1999;38: 324-8.

6 Fekety R. Guidelines for the diagnosis and management of Clostridium difficile-associated diarrhoea and colitis. Am f Gastroenterol 1997;92:73950

7 Johnson S, Sypura WD, Gerding DN, et al. Selective neutralization of a bacterial enterotoxin by serum immunoglobulin $\mathrm{A}$ in response to mucosal disease. Infect Immun 1995;63:3166-73.

8 Stubbe H, Berdoz J, Kraehenbuhl J-P, et al. Polymeric IgA is superior to monomeric IgA and IgG carrying the same variable domain in preventing Clostridium difficile toxin A damaging of T84 monlayers. F Immunol 2000;164:1952-60.

9 Aronsson B, Granström M, Möllby R, et al. Serum antibody response to Clostridium difficile toxins in patients with Clostridium difficile diarrhoea. Infection 1985;13:97-101.

10 Johnson S, Gerding DN, Janoff EN. Systemic and mucosal antibody responses to toxin A in patients infected with Clostridium difficile. F Infect Dis 1992;166:1287-94 